\title{
BMJ Open Dynamic pattern of suicide in Australia, 1986-2005: a descriptive-analytic study
}

\author{
Xin Qi, ${ }^{1,2}$ Wenbiao Hu, ${ }^{2}$ Andrew Page, ${ }^{3}$ Shilu Tong ${ }^{2}$
}

To cite: Qi X, Hu W, Page A, et al. Dynamic pattern of suicide in Australia, 19862005: a descriptive-analytic study. BMJ Open 2014;4: e005311. doi:10.1136/ bmjopen-2014-005311

- Prepublication history and additional material is available. To view please visit the journal (http://dx.doi.org/ 10.1136/bmjopen-2014005311)

Received 21 March 2014 Revised 9 July 2014 Accepted 10 July 2014
CrossMark

\footnotetext{
${ }^{1}$ School of Public Health, X'an Jiaotong University Health Science Center, Xi'an, Shaanxi, China

${ }^{2}$ School of Public Health and Social Work, Queensland University of Technology, Kelvin Grove, Queensland, Australia

${ }^{3}$ School of Science and Health, University of Western Sydney, Penrith, New South Wales, Australia
}

Correspondence to Dr Xin Qi;

chester.qi@yahoo.com

\section{ABSTRACT}

Objective: This study explores the spatiotemporal variations of suicide across Australia from 1986 to 2005 , discusses the reasons for dynamic changes, and considers future suicide research and prevention strategies.

Design: Suicide (1986-2005) and population data were obtained from the Australian Bureau of Statistics. A series of analyses were conducted to examine the suicide pattern by sex, method and age group over time and geography.

Results: Differences in suicide rates across sex, age groups and suicide methods were found across geographical areas. Male suicides were mainly completed by hanging, firearms, gases and selfpoisoning. Female suicides were primarily completed by hanging and self-poisoning. Suicide rates were higher in rural areas than in urban areas (capital cities and regional centres). Suicide rates by firearms were higher in rural areas than in urban areas, while the pattern for self-poisoning showed the reverse trend. Suicide rates had relatively stable trend for the total population and those aged between 15 and 54, while suicide decreased among 55 years and over during the study period. There was a decrease in suicides by firearms during the study period especially after 1996 when a new firearm control law was implemented, while suicide by hanging continued to increase. Areas with a high proportion of indigenous population (eg, northwest of Queensland and top north of the Northern Territory) had shown a substantial increase in suicide incidence after 1995.

Conclusions: Suicide rates varied over time and space and across sexes, age groups and suicide methods. This study provides detailed patterns of suicide to inform suicide control and prevention strategies for specific subgroups and areas of high and increased risk.

\section{INTRODUCTION}

Suicide remains a major public health issue globally, with about 1 million suicide deaths annually. ${ }^{1}$ Suicide patterns, including suicide methods, time and geographical variation, have been explored in many countries and regions, such as Brazil, $^{2}$ China, ${ }^{3}$ India, ${ }^{4}$ Russia, ${ }^{5}$ Taiwan, ${ }^{6}$ the $\mathrm{UK}^{7}$ and the USA. ${ }^{8}$ In Australia, suicide rates have fluctuated since

\section{Strengths and limitations of this study}

- Different levels of spatial scale were combined to display spatial distribution of suicide patterns; with boundary changes over the period adjusted using advanced Geographic Information Systems methods.

- Aggregate data were used. Detailed individual information was not available.

- Quality of suicide data may vary over time.

- The suicide database may not indicate the trends of suicide after 2005.

suicide registration started in the early 1920 s. $^{9-11}$ The trend of annual suicide rates from 1980 was relatively stable (around 9$10 / 100000$ ) except for a peak in 1997 (around 14.6/100 000). ${ }^{9-11}$ However, there were still approximately 2000 suicide deaths annually, mainly in male adults (25-54 years of age). Thus, it is vital to understand the variations of suicide patterns over time, space, population groups (age, sex and ethnic groups) and the possible reasons for these variations, in order to design effective suicide control and prevention programmes. Previous reports and studies have explored suicide patterns in Australia over time, ${ }^{9-12}$ methods ${ }^{13}$ and space. ${ }^{14}$ From a geographical perspective, the Australian Bureau of Statistics (ABS) suicide reports covered a long period (1921-2010) presented at the state and capital city level. ${ }^{9-11}$ However, suicide patterns at the smaller area (eg, Local Government Area, LGA) level, especially in rural and remote areas, were not routinely provided in ABS reports. A study by Cheung et $a l^{15}$ examined the spatial pattern of suicide in Australia after 2000. However, this study did not examine the suicide pattern before 2000 or by suicide methods; thus, the dynamic spatial pattern of suicide and high-risk areas of suicide by a particular method (eg, firearms) could not be demonstrated. ABS reports indicated that most suicides occur in urban areas in Australia, while fewer suicides were recorded in rural and remote areas, areas of lower population 
density. It is therefore important to select suitable spatial scales in examining the geographic pattern of suicide in Australia. The studies of spatial patterns of suicide in earlier years (eg, before 1995) used relatively large spatial scales (eg, Statistical Division rather than LGA), which may mask the spatial variation of suicide in some rural areas (eg, in Western Australia (WA) and the Northern Territory (NT)) due to their large geographic size. $^{16} 17$ The spatial patterns of suicide by different population groups and suicide methods over the longterm covering earlier years (eg, before 2000) and more recent years (after 2000) using suitable spatial scales (eg, LGA) have not yet been examined. Trends in suicide rates over time are likely to differ across population groups (eg, young or older adults) and area (eg, suicide by firearms in urban or rural areas). Thus, this study examined long-term (dynamic and static), spatiotemporal patterns of Australian national suicide, using a range of different combinations of age, time, method and location for the period 1986-2005.

\section{DESIGN}

\section{Data source}

Unit record data of suicide deaths between 1986 and 2005 were obtained from the ABS, including sex, International Classification of Disease (ICD) Code (ICD 9: 950.0-959.9 and ICD 10: X60-X84) ${ }^{18}{ }^{19}$ relating to suicide or self-inflicted injury, age, country of birth, date of suicide and Statistical Local Area (SLA) code for place of suicide occurrence. Access to unit record suicide for these variables from the ABS after 2005 was not possible, as the related procedure is under review. As SLA boundaries have changed dramatically over the study period, especially in urban areas, we chose LGA as the standard geographical unit to explore the spatial pattern of suicide. Choosing LGA as the spatial scale also aims to keep the balance between including sufficient case numbers of suicide in each geographical unit and using too large a geographical unit. Each LGA is composed of one or more SLAs, and LGA boundaries are relatively stable over the study period. The Australian Standard Geographical Classification (ASGC), updated annually, was used to incorporate SLA codes into LGA codes, and examine and adjust for SLA/LGA boundary changes over time. CDATA 2001, a product issued by ABS, provided digital boundaries and sociodemographic data of Australia (including the 1991, 1996 and 2001 population census data at SLA/LGA levels, based on the 2001 Census boundary) and was applied in the MapInfo 10.5 software package for map display ${ }^{20}$ Population data (SLA/LGA levels) in the 1986 and 2006 Censuses from ABS were merged with the 2001 Census data after adjustment for boundary changes using ASGC references. The suicide rates in different groups over time and across LGAs were then calculated. In this study, we categorised LGAs as: metropolitan areas of capital cities, regional centres (other LGA named as 'city' outside of capital cities, eg, City of Townville), or rural and remote areas (remaining LGAs).

Most areas in South Australia (SA) and NT have a very low population density and were defined as unincorporated areas by ABS at the LGA level. However, these areas were also composed of 27 SLAs according to the 2001 Census data. Thus, we applied SLA data in unincorporated areas in SA and NT to provide more detailed geographic information. In the 2001 Census, Australia was divided into 628 LGAs, plus 27 SLAs in the unincorporated areas of SA and NT.

\section{Statistical analyses}

Descriptive and mapping approaches were applied to explore the age, sex, method, time and regional-specific patterns of suicide cases and rates. First, we explored the basic pattern of suicide among different groups by calculating suicide rates, rate ratios and $95 \%$ CI to the annual mean national suicide rate over the study period using the annual average suicide number in the whole Australian population (1986-2005) as the reference group. Temporal trends of suicide rates in population groups were then examined, using yearly data and Poisson regression, offset by the natural logarithm of the population size and adjusting for year as a covariate. All the statistical analyses were implemented by SPSS 21.0. ${ }^{21}$ Finally, suicide rates at the LGA level were applied to display suicide rates by sex, age group and method using mapping approaches by MapInfo $10.5 .^{20}$ We used the annual average sex-specific rates for the whole of Australia over the entire study period as the reference to calculate age-adjusted standardised mortality ratios for both sexes.

\section{RESULTS}

This study included 45293 suicide deaths for the 20 year period. Table 1 indicates that most suicides occurred in those aged between 15 and 54 years and occurred in capital cities and regional centres, as the majority of Australian population live in urban areas. However, suicide rates in rural and remote areas were higher than in urban areas. Approximately $80 \%$ of suicides were found to be committed by males, with the majority of suicides occurring in those aged between 15 and 54 years, although older males (75-year and over) had higher suicide rates than males in other age groups. Four methods accounted for the majority of suicides: (1) firearms, airguns and other explosives (simplified as firearms, $16 \%$ of total suicides); (2) hanging (35\% of total); (3) gases and vapours (20\% of total) and (4) solid or liquid substances ( $15 \%$ of total). The rate ratio and $95 \%$ CI of suicide in each population group and by different methods were calculated, using the annual average suicide incidence in the study period in Australia as a reference (table 1 ). We also applied the $\chi^{2}$ test to assess the distribution of suicide cases by 
Table 1 Suicide deaths and rate (per 100 000) across different groups in Australia (1986-2005)

\begin{tabular}{|c|c|c|c|c|c|c|c|c|c|c|c|c|c|c|c|}
\hline \multirow[b]{3}{*}{ Population group } & \multicolumn{15}{|c|}{ Age group } \\
\hline & \multicolumn{3}{|l|}{$15-34$} & \multicolumn{3}{|l|}{$35-54$} & \multicolumn{3}{|l|}{$55-74$} & \multicolumn{3}{|c|}{75 and over } & \multicolumn{3}{|c|}{ All ages } \\
\hline & Cases & Rate & $\begin{array}{l}\text { Rate ratio } \\
(95 \% \mathrm{Cl})\end{array}$ & Cases & Rate & $\begin{array}{l}\text { Rate ratio } \\
(95 \% \mathrm{Cl})\end{array}$ & Cases & Rate & $\begin{array}{l}\text { Rate ratio } \\
(95 \% \mathrm{Cl})\end{array}$ & Cases & Rate & $\begin{array}{l}\text { Rate ratio } \\
(95 \% \mathrm{Cl})\end{array}$ & Cases & Rate & $\begin{array}{l}\text { Rate ratio } \\
(95 \% \mathrm{Cl})\end{array}$ \\
\hline \multicolumn{16}{|l|}{ By sex } \\
\hline Male & 15059 & 28.29 & 2.23 (2.19 to 2.27 ) & 12672 & 25.61 & 2.02 (1.98 to 2.06$)$ & 5986 & 22.35 & $1.77(1.72$ to 1.81$)$ & 2091 & 30.98 & 2.45 (2.34 to 2.56 ) & 35942 & 20.32 & 1.61 (1.58 to 1.63$)$ \\
\hline Female & 3242 & 6.12 & 0.48 (0.47 to 0.50$)$ & 3556 & 7.14 & 0.56 (0.55 to 0.58$)$ & 1818 & 6.48 & 0.51 (0.49 to 0.54$)$ & 682 & 6.14 & 0.49 (0.45 to 0.52$)$ & 9351 & 5.17 & 0.41 (0.40 to 0.42$)$ \\
\hline \multicolumn{16}{|l|}{ By region } \\
\hline Capital cities & 11267 & 16.28 & $1.29(1.26$ to 1.31$)$ & 9736 & 15.68 & $1.24(1.21$ to 1.27$)$ & 4568 & 14.21 & $1.12(1.09$ to 1.16$)$ & 1674 & 15.45 & $1.22(1.16$ to 1.28$)$ & 27332 & 12.32 & 0.97 (0.96 to 0.99$)$ \\
\hline Regional centres & 3423 & 17.57 & 1.39 (1.34 to 1.44$)$ & 3269 & 17.72 & $1.40(1.35$ to 1.45$)$ & 1550 & 13.65 & $1.03(1.03$ to 1.14$)$ & 584 & 15.96 & $1.26(1.16$ to 1.37$)$ & 8869 & 12.86 & $1.02(1.00$ to 1.04$)$ \\
\hline Rural and remote areas & 3611 & 20.58 & 1.63 (1.57 to 1.68$)$ & 3223 & 17.23 & $1.36(1.31$ to 1.41$)$ & 1686 & 14.88 & 1.18 (1.12 to 1.23$)$ & 515 & 15.37 & 1.21 (1.11 to 1.32$)$ & 9092 & 13.55 & $1.07(1.05$ to 1.09$)$ \\
\hline \multicolumn{16}{|l|}{ By methods } \\
\hline $\begin{array}{l}\text { Firearms and other } \\
\text { explosives }\end{array}$ & 2795 & 2.63 & 0.21 (0.20 to 0.22$)$ & 2285 & 2.30 & 0.18 (0.18 to 0.19$)$ & 1674 & 3.05 & $0.24(0.23$ to 0.25$)$ & 556 & 3.11 & 0.25 (0.23 to 0.27$)$ & 7348 & 2.07 & $0.16(0.16$ to 0.17$)$ \\
\hline Gases and vapours & 3457 & 3.25 & $0.26(0.25$ to 0.27$)$ & 4104 & 4.13 & $0.33(0.32$ to 0.34$)$ & 1277 & 2.33 & $0.18(0.17$ to 0.20$)$ & 375 & 2.10 & $0.17(0.15$ to 0.18$)$ & 9214 & 2.60 & $0.20(0.20$ to 0.21$)$ \\
\hline Hanging & 7366 & 6.93 & 0.55 (0.54 to 0.56$)$ & 4927 & 4.96 & 0.39 (0.38 to 0.41$)$ & 2301 & 4.20 & 0.33 (0.32 to 0.35$)$ & 901 & 5.05 & 0.40 (0.37 to 0.43$)$ & 15620 & 4.40 & 0.35 (0.34 to 0.35$)$ \\
\hline $\begin{array}{l}\text { Solid or liquid } \\
\text { substances }\end{array}$ & 2166 & 2.04 & $0.16(0.16$ to 0.17$)$ & 2863 & 2.88 & $0.23(0.22$ to 0.24$)$ & 1333 & 2.43 & $0.19(0.18$ to 0.20$)$ & 434 & 2.43 & $0.19(0.18$ to 0.21$)$ & 6807 & 1.92 & $0.15(0.15$ to 0.15$)$ \\
\hline Other & 2517 & 1.26 & $0.19(0.18$ to 0.20$)$ & 2049 & 2.06 & 0.16 (0.16 to 0.17$)$ & 1219 & 2.22 & 0.18 (0.17 to 0.19$)$ & 507 & 2.84 & 0.23 (0.21 to 0.25$)$ & 6294 & 1.78 & 0.14 (0.14 to 0.14$)$ \\
\hline By region and by sex & & & & & & & & & & & & & & & \\
\hline \multicolumn{16}{|l|}{ Male } \\
\hline Capital cities & 9072 & 26.66 & 2.08 (2.03 to 2.13 ) & 7439 & 24.59 & $1.92(1.87$ to 1.97$)$ & 3358 & 21.86 & 1.71 (1.65 to 1.77$)$ & 1179 & 30.02 & 2.35 (2.22 to 2.49 ) & 21107 & 19.63 & 1.53 (1.51 to 1.56$)$ \\
\hline Regional centres & 2868 & 29.90 & 2.33 (2.25 to 2.42$)$ & 2593 & 28.60 & 2.23 (2.15 to 2.32$)$ & 1213 & 22.21 & 1.74 (1.64 to 1.84$)$ & 468 & 32.80 & 2.57 (2.35 to 2.81$)$ & 7173 & 21.39 & $1.67(1.63$ to 1.71$)$ \\
\hline Rural/remote areas & 3119 & 32.46 & 2.72 (2.62 to 2.82 ) & 2640 & 25.99 & 2.16 (2.08 to 2.24$)$ & 1415 & 23.73 & 1.94 (1.84 to 2.04$)$ & 444 & 31.82 & 2.60 (2.37 to 2.85$)$ & 7662 & 21.39 & 1.77 (1.73 to 1.82$)$ \\
\hline \multicolumn{16}{|l|}{ Female } \\
\hline Capital cities & 2195 & 6.40 & 0.50 (0.48 to 0.52$)$ & 2297 & 7.39 & 0.58 (0.55 to 0.60$)$ & 1210 & 7.33 & $0.57(0.54$ to 0.61$)$ & 495 & 7.26 & 0.57 (0.52 to 0.62$)$ & 6225 & 5.58 & $0.44(0.42$ to 0.45$)$ \\
\hline Regional centres & 555 & 5.75 & 0.45 (0.42 to 0.49$)$ & 676 & 7.37 & 0.58 (0.53 to 0.62$)$ & 337 & 5.83 & $0.46(0.41$ to 0.51$)$ & 116 & 5.27 & $0.41(0.34$ to 0.50$)$ & 1696 & 4.91 & 0.38 (0.37 to 0.40$)$ \\
\hline Rural/remote areas & 492 & 5.43 & 0.43 (0.39 to 0.47$)$ & 583 & 6.12 & 0.51 (0.47 to 0.55$)$ & 271 & 4.71 & 0.39 (0.34 to 0.43$)$ & 71 & 3.41 & 0.28 (0.22 to 0.35$)$ & 1430 & 4.13 & 0.34 (0.33 to 0.36$)$ \\
\hline \multicolumn{16}{|l|}{ By methods and by region } \\
\hline \multicolumn{16}{|l|}{ Capital cities } \\
\hline $\begin{array}{l}\text { Firearms and other } \\
\text { explosives }\end{array}$ & 1148 & 1.66 & $0.13(0.12$ to 0.14$)$ & 913 & 1.47 & $0.12(0.11$ to 0.12$)$ & 626 & 1.95 & $0.15(0.14$ to 0.17$)$ & 211 & 1.95 & $0.16(0.14$ to 0.18$)$ & 2908 & 1.31 & $0.10(0.10$ to 0.11$)$ \\
\hline Gases and vapours & 2299 & 3.32 & $0.26(0.25$ to 0.27$)$ & 2420 & 3.90 & 0.31 (0.30 to 0.32$)$ & 732 & 2.28 & $0.18(0.17$ to 0.19$)$ & 222 & 2.05 & $0.16(0.14$ to 0.19$)$ & 5674 & 2.56 & 0.20 (0.20 to 0.21$)$ \\
\hline Hanging & 4339 & 6.27 & $0.50(0.48$ to 0.51$)$ & 3017 & 4.86 & $0.38(0.37$ to 0.40$)$ & 1470 & 4.57 & 0.36 (0.34 to 0.38$)$ & 591 & 5.45 & 0.43 (0.40 to 0.47$)$ & 9478 & 4.27 & $0.30(0.30$ to 0.31$)$ \\
\hline Solid or liquid substances & 1547 & 2.24 & $0.18(0.17$ to 0.19$)$ & 1864 & 3.00 & $0.24(0.23$ to 0.25$)$ & 901 & 2.80 & $0.22(0.21$ to 0.24$)$ & 284 & 2.62 & 0.21 (0.19 to 0.23$)$ & 4600 & 2.07 & $0.16(0.16$ to 0.17$)$ \\
\hline Other & 1934 & 2.79 & 0.22 (0.21 to 0.23$)$ & 1522 & 2.45 & 0.19 (0.18 to 0.20$)$ & 839 & 2.61 & 0.21 (0.19 to 0.22$)$ & 366 & 3.38 & $0.27(0.24$ to 0.30$)$ & 4672 & 2.11 & $0.17(0.16$ to 0.17$)$ \\
\hline \multicolumn{16}{|l|}{ Regional centres } \\
\hline $\begin{array}{l}\text { Firearms and other } \\
\text { explosives }\end{array}$ & 603 & 3.09 & $0.25(0.23$ to 0.27$)$ & 495 & 2.68 & $0.21(0.20$ to 0.23$)$ & 368 & 3.24 & $0.26(0.23$ to 0.28$)$ & 131 & 3.58 & $0.28(0.24$ to 0.33$)$ & 1606 & 2.33 & $0.19(0.18$ to 0.19$)$ \\
\hline Gases and vapours & 631 & 3.24 & 0.26 (0.24 to 0.28$)$ & 861 & 4.67 & 0.37 (0.35 to 0.40$)$ & 275 & 2.42 & 0.19 (0.17 to 0.22$)$ & 91 & 2.49 & 0.20 (0.16 to 0.24$)$ & 1858 & 2.70 & 0.21 (0.20 to 0.22$)$ \\
\hline Hanging & 1502 & 7.71 & 0.61 (0.58 to 0.64$)$ & 1026 & 5.56 & 0.44 (0.41 to 0.47$)$ & 456 & 4.02 & $0.32(0.29$ to 0.35$)$ & 187 & 5.11 & 0.40 (0.35 to 0.46$)$ & 3200 & 4.65 & 0.37 (0.36 to 0.38$)$ \\
\hline Solid or liquid substances & 344 & 1.77 & $0.14(0.13$ to 0.16$)$ & 570 & 3.09 & 0.25 (0.23 to 0.27$)$ & 258 & 2.27 & $0.18(0.16$ to 0.20$)$ & 92 & 2.51 & $0.20(0.16$ to 0.24$)$ & 1268 & 1.84 & $0.15(0.14$ to 0.15$)$ \\
\hline Other & 343 & 1.76 & $0.14(0.13$ to 0.16$)$ & 317 & 1.72 & $0.14(0.12$ to 0.15$)$ & 193 & 1.70 & $0.14(0.12$ to 0.16$)$ & 83 & 2.27 & 0.18 (0.15 to 0.22$)$ & 937 & 1.36 & 0.11 (0.10 to 0.12$)$ \\
\hline \multicolumn{16}{|l|}{ Rural/remote areas } \\
\hline $\begin{array}{l}\text { Firearms and other } \\
\text { explosives }\end{array}$ & 1044 & 5.95 & 0.47 (0.44 to 0.50$)$ & 877 & 4.69 & 0.37 (0.35 to 0.40$)$ & 680 & 6.00 & 0.48 (0.44 to 0.51$)$ & 214 & 6.39 & 0.51 (0.44 to 0.52$)$ & 2834 & 4.22 & 0.33 (0.32 to 0.35$)$ \\
\hline Gases and vapours & 527 & 3.00 & $0.24(0.22$ to 0.26$)$ & 823 & 4.40 & $0.35(0.33$ to 0.37$)$ & 270 & 2.38 & $0.19(0.17$ to 0.21$)$ & 62 & 1.85 & 0.15 (0.11 to 0.19$)$ & 1682 & 2.51 & $0.20(0.19$ to 0.21$)$ \\
\hline Hanging & 1525 & 8.69 & 0.69 (0.65 to 0.72$)$ & 884 & 4.73 & $0.37(0.35$ to 0.40$)$ & 375 & 3.31 & $0.26(0.24$ to 0.29$)$ & 123 & 3.67 & $0.29(0.24$ to 0.35$)$ & 2942 & 4.38 & 0.35 (0.33 to 0.36$)$ \\
\hline Solid or liquid substances & 275 & 1.57 & $0.12(0.11$ to 0.14$)$ & 429 & 2.29 & 0.18 (0.17 to 0.20$)$ & 174 & 1.54 & $0.12(0.11$ to 0.14$)$ & 58 & 1.73 & 0.14 (0.11 to 0.18$)$ & 939 & 1.40 & $0.11(0.10$ to 0.12$)$ \\
\hline Other & 240 & 1.37 & $0.11(0.10$ to 0.12$)$ & 210 & 1.12 & $0.09(0.08$ to 0.10$)$ & 187 & 1.65 & $0.13(0.11$ to 0.15$)$ & 58 & 1.73 & $0.14(0.11$ to 0.18$)$ & 695 & 1.04 & $0.08(0.08$ to 0.09$)$ \\
\hline
\end{tabular}

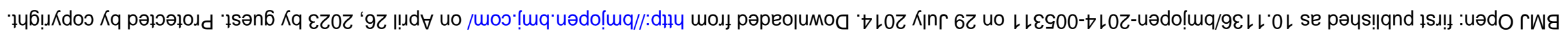




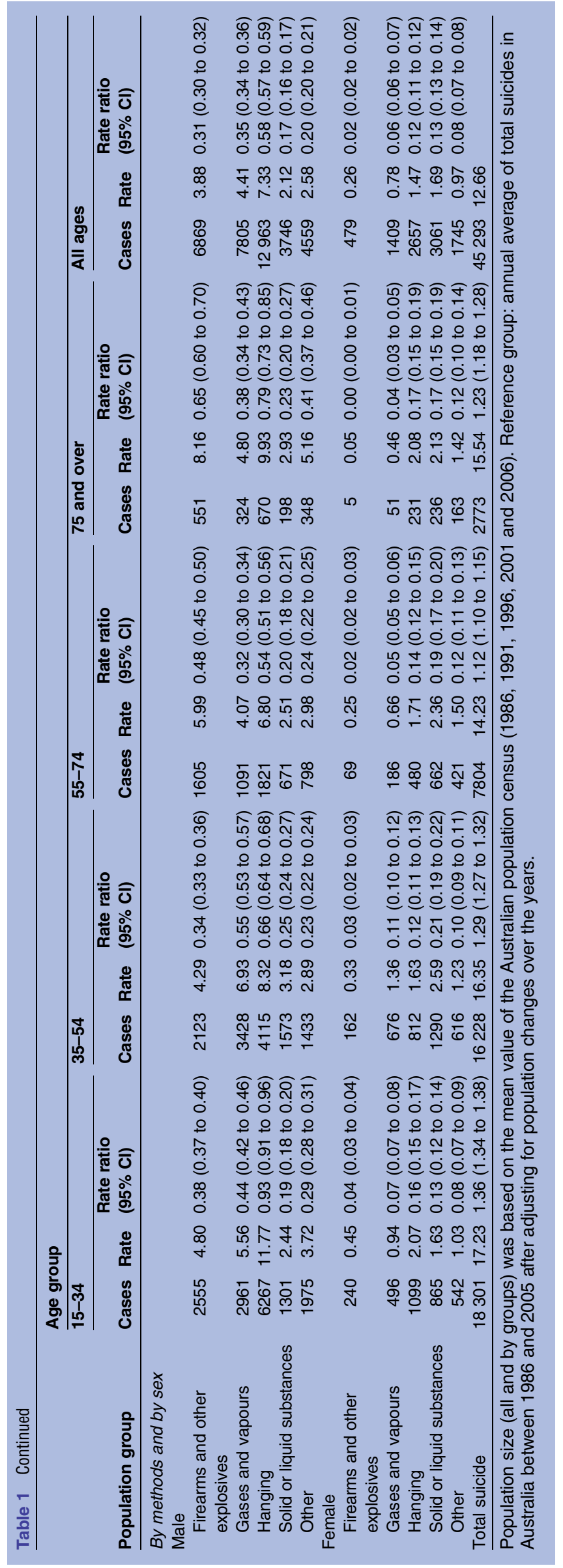

population groups and method (all differences were statistically significant).

Figure 1 shows time series trends by different groups. There was a peak in the suicide rate among the total population during the period 1996-1998, particularly in males aged from 15 to 34 years (Figure 1A), males in rural and remote areas (Figure 1B) and suicide committed by hanging (Figure 1C). In the early years of the study period, suicide incidence among those aged 55 years and over was higher than in those below 55 years; however, rates decreased over time and were lower than in those of young and middle-aged adults after 2000, particularly in males (Figure 1A). Suicide rates among those aged 15-34 years had peaks in 1997 and 1998 (especially for males peaking at approximately $34 / 100000$ and 21/100 000, respectively, for total suicide rates) and kept relatively steady in other years (25-28/ 100000 for males and 14-17/100 000 for the total population; Figure 1A). In 1986, firearms and other explosives were the most common methods of suicide in Australia (over 6/100000 among males). However, the rate dropped to around 2/100 000 in 2005. In contrast, male suicide rates by hanging rose from 3.8/100 000 in 1986 to 9.4/100 000 in 2005, after experiencing a peak of 10.6/ 100000 in 1998 (Figure 1C). Suicide rates by hanging in males dropped after 1997 but were still higher than in the early years of the study period. Figure 2 used 5-year periods to explore method-specific suicide by age groups and urban-rural differences. Suicide rates by firearms decreased over the study period, especially among those aged 15-54 years and in rural and remote areas (figure 2A, B), while suicide by hanging increased dramatically and reached a peak during 1996-2000, especially among those aged 15-54 years (figure 2A). For those aged 55 years and older, suicide rates by hanging and firearms remained more stable than for those aged 54 years and younger over the study period. Suicide rates by gases and vapours, solid and liquid substances fluctuated over the study period among all population groups (figure 2A,B). Further detailed stratification of suicide incidence trends over time in each population group and suicide methods is presented in online supplementary materials 1 and 2 . Poisson regression was implemented to examine the time series trend of suicide rates across population groups and by methods (table 2). Suicide rates by sex, age 55 years and over, urban residence, and suicide by firearms, solid and liquid substances decreased over time. However, suicide rates by hanging increased significantly. Table 3 indicated that male suicide rates by firearms kept decreasing across the whole study period, especially from the period 1991-1995 to the period 1996-2000.

Figure 3 shows that among those aged 15-34 years, the north and central south areas of the NT, the northeast and some southern parts of WA, the northwest and central inland areas of Queensland (QLD) and some inland areas of New South Wales (NSW) had higher suicide (A2). The patterns were also similar for males (NT, QLD and WA in B1). Those aged between 35 and 
Figure 1 Suicide rates over time and subgroups (per 100 000). (A) Sex and age groups; (B) sex and urban-rural differences and (C) sex and methods.
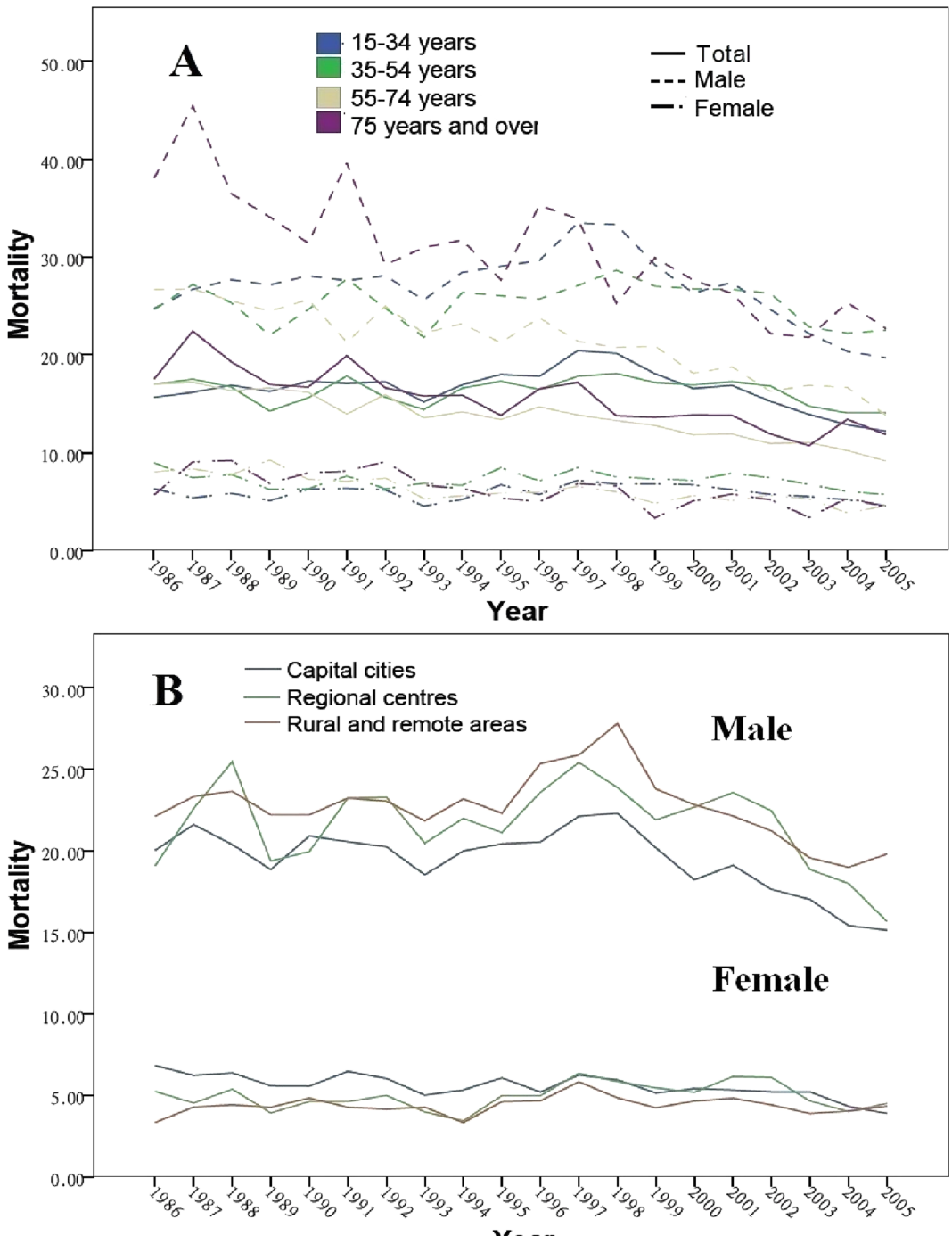

Year

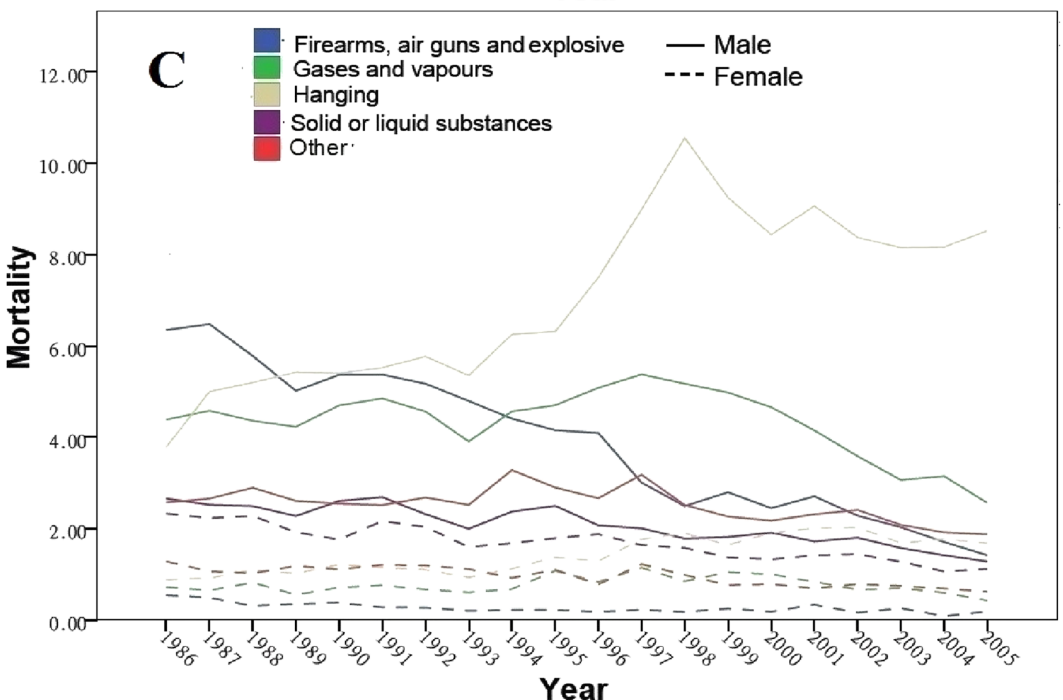

Year

NT and SA had no suicide data. Compared with males, a greater number of areas had no female suicide data (B2). Rural and remote areas had lower rates of suicide by self-poisoning than urban areas, except for some LGAs in inland QLD, east SA and south WA (C2). 
Figure 2 Suicide rates over time and methods (per 100000 , annual average). (A) Methods and age groups and $(B)$ methods and urban-rural difference.
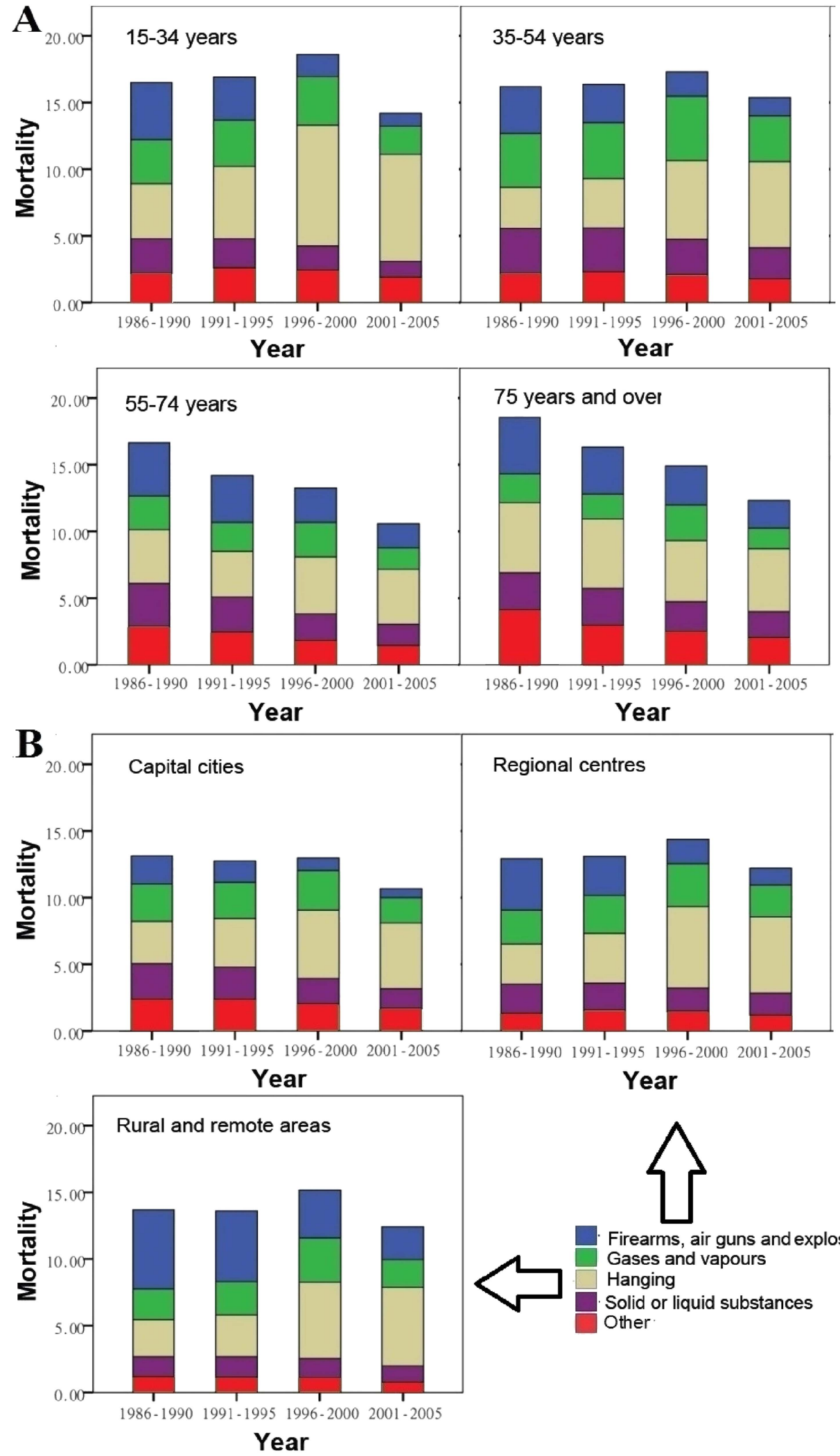

Firearms, air guns and explosive Gases and vapours

Hanging

Solid or liquid substances Other
As suicide rates by firearms and by hanging had more significant changes over time than other methods and by population groups, we also explored whether this trend existed in spatial scales over time by stratifying the whole study period into four 5-year periods (figure 4).
Figure $4 \mathrm{~A}$ shows that the suicide rate by hanging was low in the early years of the study period (A1), and very few suicides occurred in the rural and remote areas of WA, NT, QLD and NSW. However, the suicide rate by hanging increased in most areas of Australia since 1986. 
Table 2 Suicide rate change over time (population groups and suicide methods)

\begin{tabular}{lllr}
\hline & RR & 95\% Cl & p Value \\
\hline All suicide & 0.99 & 0.99 to 0.99 & $<0.001$ \\
Male & 0.99 & 0.99 to 0.99 & $<0.001$ \\
Female & 0.99 & 0.99 to 0.99 & $<0.001$ \\
Age 15-34 & 0.99 & 0.99 to 1.00 & $<0.001$ \\
Age 35-54 & 1.00 & 0.99 to 1.00 & 0.009 \\
Age 55-74 & 0.97 & 0.97 to 0.98 & $<0.001$ \\
Age 75 and over & 0.97 & 0.97 to 0.98 & $<0.001$ \\
Urban areas & 0.99 & 0.99 to 0.99 & 0.001 \\
Regional areas & 1.00 & 0.99 to 1.00 & 0.019 \\
Rural and remote areas & 1.00 & 0.99 to 1.00 & 0.022 \\
Firearms & 0.93 & 0.93 to 0.94 & $<0.001$ \\
Hanging & 1.04 & 1.03 to 1.04 & $<0.001$ \\
Gas and vapour & 0.99 & 0.98 to 0.99 & $<0.001$ \\
Solid or liquid substances & 0.97 & 0.96 to 0.97 & $<0.001$ \\
Other methods & 0.98 & 0.98 to 0.98 & $<0.001$ \\
\hline Reference group: suicide 19.96 & &
\end{tabular}

Reference group: suicide in 1986 for each population group.

RR, Relative Risk.

North of WA, the NT and SA, north of QLD and even urban LGAs had much higher suicide rates between 1996 and 2005 compared with rates in earlier years. Some areas (eg, Mornington Shire (MTS) of northwest QLD, Bathurst-Melville (BM) of NT) had dramatic increases in suicide by hanging. Both these areas experienced an increase in the number of suicide cases (especially for suicide by hanging) between 1996 and 2005

\begin{tabular}{|c|c|c|c|c|}
\hline $\begin{array}{l}\text { Population } \\
\text { group }\end{array}$ & $\begin{array}{l}\text { Time } \\
\text { period }\end{array}$ & RR & $95 \% \mathrm{Cl}$ & p Value \\
\hline \multirow[t]{3}{*}{ 15-34 years } & 2001-2005 & 0.22 & 0.08 to 0.36 & $<0.001$ \\
\hline & 1996-2000 & 0.39 & 0.28 to 0.51 & $<0.001$ \\
\hline & 1991-1995 & 0.78 & 0.69 to 0.87 & $<0.001$ \\
\hline \multirow[t]{3}{*}{ 35-54 years } & 2001-2005 & 0.39 & 0.26 to 0.51 & $<0.001$ \\
\hline & 1996-2000 & 0.52 & 0.40 to 0.64 & $<0.001$ \\
\hline & 1991-1995 & 0.83 & 0.72 to 0.94 & 0.001 \\
\hline \multirow[t]{3}{*}{$55-74$ years } & 2001-2005 & 0.43 & 0.28 to 0.57 & $<0.001$ \\
\hline & 1996-2000 & 0.63 & 0.49 to 0.76 & $<0.001$ \\
\hline & 1991-1995 & 0.88 & 0.75 to 1.01 & 0.049 \\
\hline 75 years and & 2001-2005 & 0.45 & 0.21 to 0.69 & $<0.001$ \\
\hline \multirow[t]{2}{*}{ over } & 1996-2000 & 0.66 & 0.43 to 0.89 & $<0.001$ \\
\hline & 1991-1995 & 0.83 & 0.59 to 1.06 & 0.103 \\
\hline \multirow[t]{3}{*}{ Capital cities } & 2001-2005 & 0.33 & 0.21 to 0.45 & $<0.001$ \\
\hline & 1996-2000 & 0.46 & 0.35 to 0.57 & $<0.001$ \\
\hline & 1991-1995 & 0.78 & 0.69 to 0.88 & $<0.001$ \\
\hline \multirow{3}{*}{$\begin{array}{l}\text { Regional } \\
\text { centres }\end{array}$} & 2001-2005 & 0.32 & 0.17 to 0.48 & $<0.001$ \\
\hline & 1996-2000 & 0.47 & 0.33 to 0.61 & $<0.001$ \\
\hline & 1991-1995 & 0.78 & 0.65 to 0.90 & $<0.001$ \\
\hline \multirow{3}{*}{$\begin{array}{l}\text { Rural and } \\
\text { remote areas }\end{array}$} & 2001-2005 & 0.41 & 0.29 to 0.53 & $<0.001$ \\
\hline & 1996-2000 & 0.61 & 0.50 to 0.72 & $<0.001$ \\
\hline & 1991-1995 & 0.91 & 0.81 to 1.00 & 0.048 \\
\hline
\end{tabular}

(27 in MTS, 23 males and 26 by hanging; 23 in BM, 22 males and 20 by hanging), compared with the period between 1986 and 1995 (4 in MTS, male and 3 by hanging; 3 in BM, male and by hanging). Suicide rates by hanging in MTS increased from 28.79 (1986-1995, annual average) to 236.32/100 000 (1996-2005, annual average); and in BM it increased from 14.10 (19861995, annual average) to $86.39 / 100000$ (1996-2005, annual average). However, the trend of suicide by firearms was opposite to that of suicide by hanging (figure 4B), especially in SA and NT, north and inland areas in NSW and QLD, and middle of WA (B1 and B2). In general, unincorporated NT and SA had a greater number of suicide cases after 1996 (123 from 1996 to 2005) compared with the period before 1996 (22 from 1986 to 1995$)$.

\section{DISCUSSION}

This study explored suicide patterns for a range of different combinations of age, time, method and location in Australia, using dynamic (trends over time) and static (averages over the entire study period) approaches. Males accounted for most suicides, and the suicide rate was higher among young and middle-aged adults, in rural and remote areas, more commonly by hanging and by firearms. The suicide rate among those aged 55 years and over declined substantially over the study period, especially for males. Suicide by firearms decreased during the study period, while suicide by hanging kept increasing, especially in males and in rural and remote areas. The spatial and spatiotemporal patterns of suicide were consistent with the yearly mean and temporal trends of suicide among different groups.

Elderly and upper middle-aged adults (55 years and over) usually report experiencing more loneliness and other health issues (eg, chronic diseases) compared with the younger age population, which may lead to psychiatric symptoms, for example, anxiety, sense of hopelessness and despair. ${ }^{22} 23$ Older adults may be less likely to seek psychiatric support when they have relevant symptoms, especially in earlier years (eg, before the mid-1990s). ${ }^{24}$ However, suicide rates among this age group gradually decreased in the study period, especially after 2000, occurring contemporaneously with an increased use of antidepressants among older adults. ${ }^{25}$ Antidepressants can reduce psychological disorders, for example, depression and suicidal behaviours among the elderly, especially when combined with other interventions (eg, counselling and family support). ${ }^{26}$ Selective serotonin reuptake inhibitors have less side effects (eg, cardiovascular impairment and drug interactions) than other drugs, and have been widely recommended by clinics to older adults. ${ }^{27} 28$ Studies in other countries have also provided evidence about the protective effect of antidepressants on severe depression and suicidal behaviour, although treatment of other levels of depression are still not clear. ${ }^{29} 30$ 
Figure 3 Suicide rates among different groups across Australia (1986-2005).

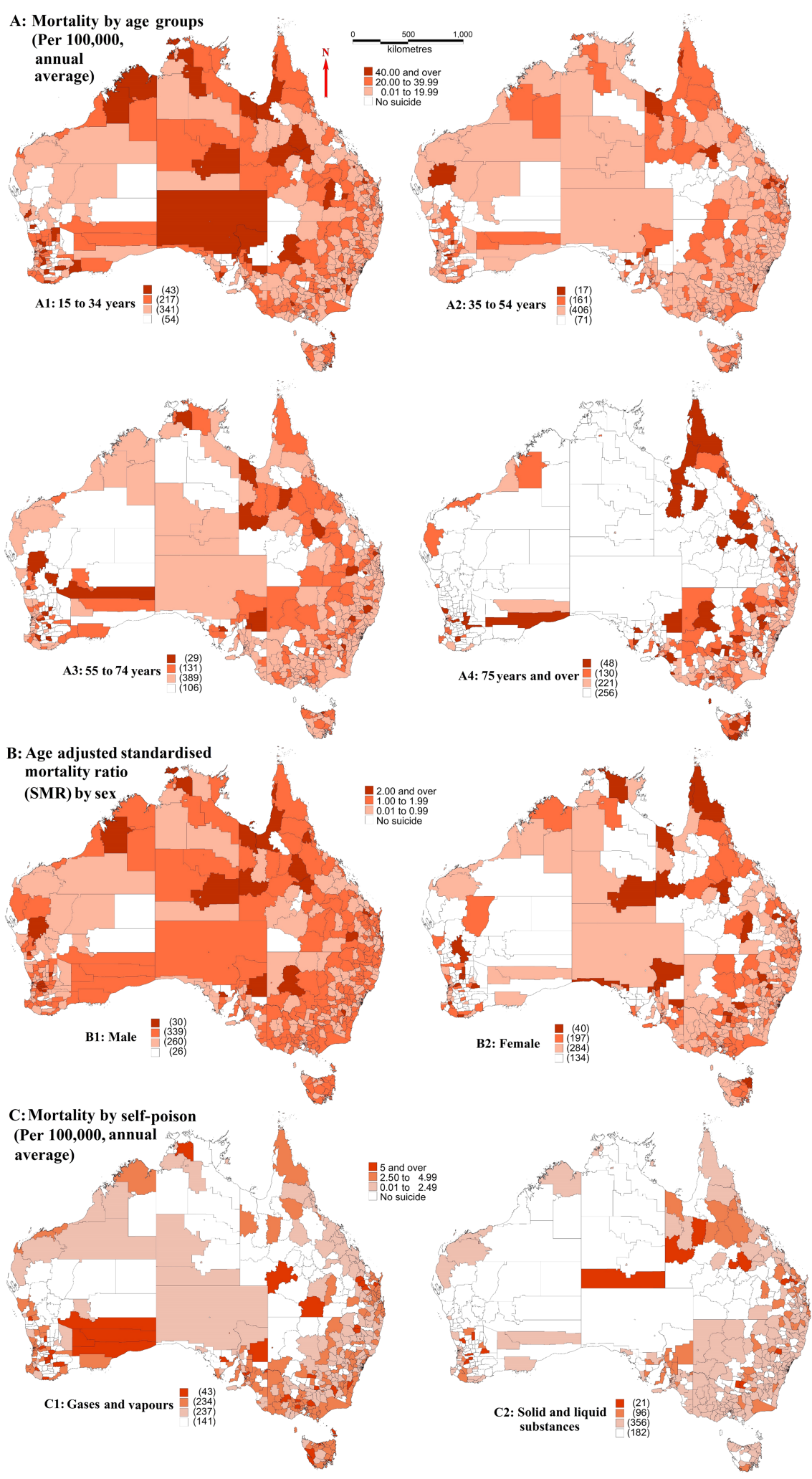

Suicide rates by firearms decreased over the study period while those by hanging increased, especially among those aged 54 years and younger. A study in Victoria indicated that a decreased registration of firearms and lower suicide rates were significantly correlated from 1997 to $2000 .{ }^{31}$ Before 1996, the importation of firearms was controlled by the Commonwealth, and the sales and possession of firearms were regulated by states and territories in Australia. ${ }^{32}$ Some states had lag in processing firearm control in responding to the Commonwealth regulation. ${ }^{33}$ The Port Arthur Massacre in Tasmania led to the enactment of The National Firearms Agreement in 1996, which regulated firearm sales, registration, storage and bans on specific types of 
Figure 4 Suicide rates by self-harm over time and across space in Australia (1986-2005).

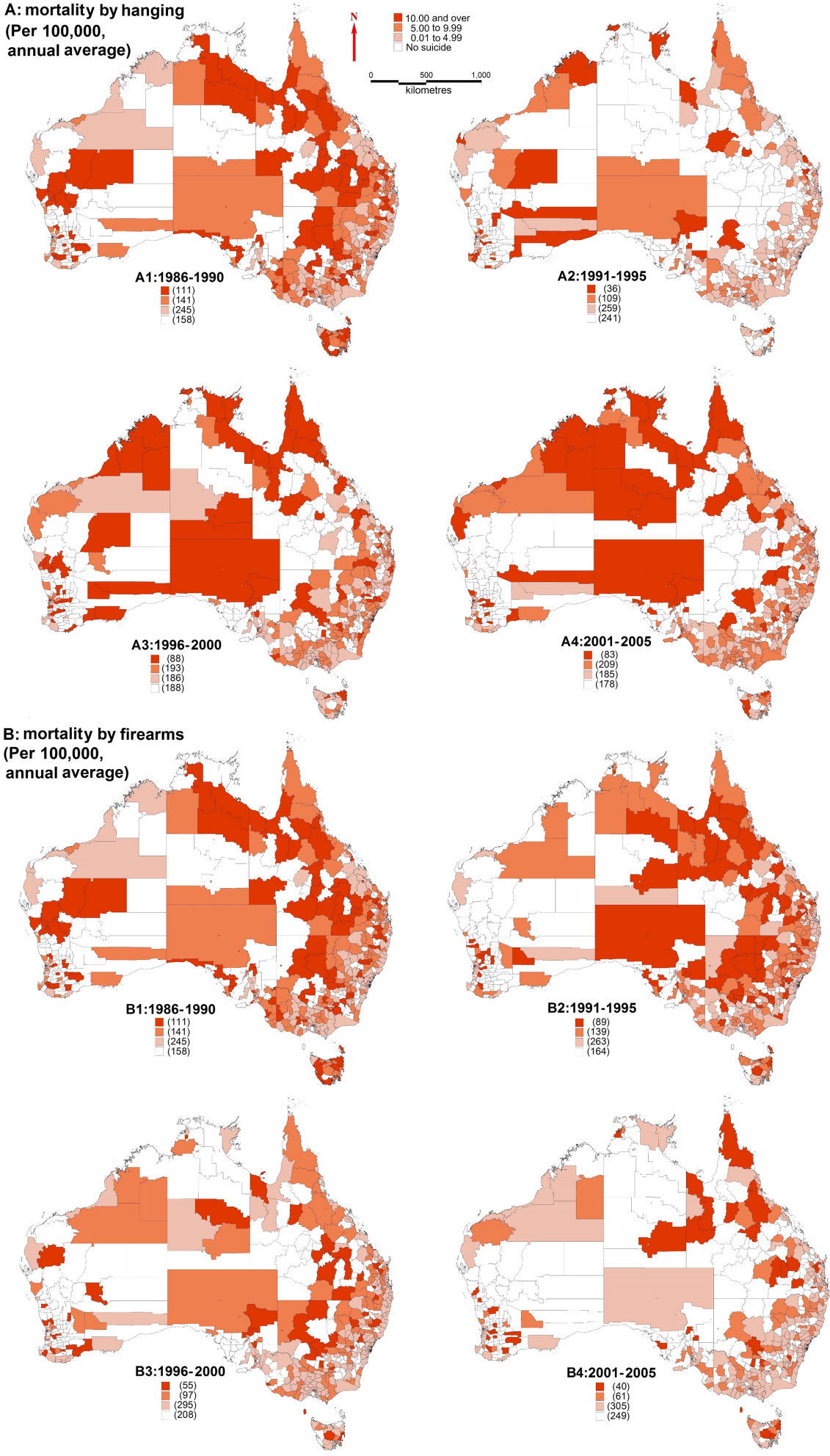

firearms nationally. ${ }^{34}$ Our study found a sharper decline in male suicide rates by firearms for the period 19911995 to the period 1996-2000 than for earlier periods (eg, the period 1991-1995 compared with the period 1986-1990), suggestive of a sustained impact of the firearm law enforcement after $1996 .^{31}$ Other studies have suggested that the decreased firearm suicide rates in young adults were accompanied by rising suicide rates by other methods at the national and local levels. ${ }^{35} 36$ Our study also found this trend, especially among males. Similarly, other countries experienced decreases in suicide rates by firearms and increases in suicide rates by hanging over time. ${ }^{37} 38$ This may be due to substitution of methods (eg, hanging) for firearms, especially after 1996 when the availability of firearms dropped in Australia. ${ }^{39}$ Suicide rates by firearms in rural areas (with 
a higher availability of firearms) remained higher than suicide rates by firearms in urban areas. More evidence, including the interaction between socioeconomic changes and suicide methods, still needs to be assessed, especially for recent years.

Only a small percentage of the population and suicide cases was of those aged 75 years and over; thus, many LGAs had no suicides, or a higher suicide rate among older adults, especially in rural and remote areas. Areas with a higher risk of suicide also often have a lower socioeconomic status, along with a higher proportion of indigenous population. ${ }^{14}$ Our previous study indicated that MTS in QLD and BM in the north of NT showed a much higher suicide risk, proportion of indigenous population and lower socioeconomic status than did the national average, and both were indicated as high-risk clusters using spatial cluster analysis (1999-2003). ${ }^{14}$ Suicide by hanging has also increased in indigenous communities, similar to other areas and population groups. ${ }^{38}$

Misclassification of suicide as the cause of death may also influence results. For example, Williams et $a t^{40}$ reported that suicide rates in QLD from the Queensland Suicide Register (QSR) were higher than those based on ABS data, with the disparity attributable to information management and definition of suicidal behaviours. Thus, the QLD suicide rate using ABS data was lower than that using the QSR database, especially after 2000. However, the ABS had a higher standard for evaluating the causes of deaths, for example, complete documents from hospital or police, which confirmed the accuracy of information of the current suicide database. ${ }^{41}$ To ensure the consistency of the suicide data across different states, the present study was restricted to ABS suicide data.

Recommendations on future research and public interventions can be proposed based on the results of this study. First, more details (eg, health and financial status, alcohol and drugs use, and family conflicts history) of suicide victims need to be acquired to help public health policymakers and health workers design and implement suicide control and prevention strategies targeting particular population groups (eg, male young adults) and areas (eg, indigenous communities). Suicide by firearms remains a significant method especially in rural and remote areas. Gatekeeper education and training in the rural primary healthcare setting may also be an approach in the identification of local vulnerable populations potentially at risk of suicidal behaviour. Education of primary health workers and the general population is important in reducing suicidal behaviours, ${ }^{42-45}$ and the effectiveness of health education programmes needs to be assessed locally. These activities should be explored at a local level, especially in high-risk areas and population groups, to assess and improve the effectiveness of suicide prevention programmes. Socioeconomic variables (eg, income and unemployment ${ }^{46 \quad 47}$ and environmental factors (eg, temperature, rainfall $)^{48-50}$ are also associated with suicide. The association of these factors with suicide by geographic markers should also be addressed by time series analysis and spatial modelling analysis. This study has explored patterns of suicide across population groups and by suicide methods over time and space; it has also shown important differences by high-risk population groups, local areas and specific suicide methods. Suicide is a complex issue, and cross-sectoral and multidisciplinary approaches also need to incorporate this geographic variability in key sociodemographic and behavioural antecedents.

Contributors $X Q$ designed the study, implemented all statistical analyses and drafted the manuscript. ST conceptualised the idea and revised the study protocol, especially the research design and data analysis. WH provided advice on statistical analyses and interpretation of the results. AP helped in interpreting the results and drafting the manuscript.

Funding This research received no specific grant from any funding agency in the public, commercial or not-for-profit sectors.

Competing interests $X Q$ was funded by the QUT Postgraduate Research Award Scholarship, and ST was supported by an NHMRC Research Fellowship (\#553043)

Ethics approval Ethical approval was granted by the Human Research Ethics Committee, Queensland University of Technology.

Provenance and peer review Not commissioned; externally peer reviewed.

Data sharing statement No additional data are available.

Open Access This is an Open Access article distributed in accordance with the Creative Commons Attribution Non Commercial (CC BY-NC 4.0) license, which permits others to distribute, remix, adapt, build upon this work noncommercially, and license their derivative works on different terms, provided the original work is properly cited and the use is non-commercial. See: http:// creativecommons.org/licenses/by-nc/4.0/

\section{REFERENCES}

1. World Health Organization. Suicide prevention (SUPRE). 2012 http://www.who.int/mental_health/prevention/suicide/suicideprevent/ en/index.html (assessed 8 Sep 2012).

2. Bando DH, Brunoni AR, Benseñor IM, et al. Suicide rates and income in São Paulo and Brazil: a temporal and spatial epidemiologic analysis from 1996 to 2008. BMC Psychiatry 2012;12:127.

3. Phillips MR, Li X, Zhang Y. Suicide rates in China, 1995-99. Lancet 2002;359:835-40.

4. Patel V, Ramasundarahettige C, Vijayakumar L, et al. Suicide mortality in India: a nationally representative survey. Lancet 2012;379:2343-51.

5. Pridemore WA, Spivak AL. Patterns of suicide mortality in Russia. Suicide Life Threat Behav 2003;33:132-50.

6. Chang SS, Sterne JA, Wheeler BW, et al. Geography of suicide in Taiwan: spatial patterning and socioeconomic correlates. Health Place 2011;17:641-50.

7. Gunnell D, Wheeler B, Chang SS, et al. Changes in the geography of suicide in young men: England and Wales 1981-2005. $\mathrm{J}$ Epidemiol Community Health 2012;66:536-43.

8. Miller M, Azrael D, Barber C. Suicide mortality in the United States: the importance of attending to method in understanding population-level disparities in the burden of suicide. Annu Rev Public Health 2012;33:393-408.

9. ABS. 3309.0 Suicides, Australia, 1921 to 1998. Canberra, Australia: Australian Bureau of Statistics, 2000.

10. ABS. 3309.0. Suicides, Australia, 2005. Canberra, Australia: Australian Bureau of Statistics, 2007.

11. ABS. 3309.0. Suicides, Australia, 2010. Canberra, Australia: Australian Bureau of Statistics, 2012.

12. Spittal MJ, Pirkis J, Miller M, et al. Declines in the lethality of suicide attempts explain the decline in suicide deaths in Australia. PLOS ONE 2012;7:e44565. 
13. Large MM, Nielssen OB. Suicide in Australia: meta-analysis of rates and methods of suicide between 1988 and 2007. Med J Aust 2010;192:432-7.

14. Qi X, Hu W, Page A, et al. Spatial clusters of suicide in Australia. BMC Psychiatry 2012;12:86.

15. Cheung YT, Spittal MJ, Pirkis J, et al. Spatial analysis of suicide mortality in Australia: investigation of metropolitan-rural-remote differentials of suicide risk across states/territories. Soc Sci Med 2012;75:1460-8.

16. Wilkinson D, Hiller J, Moss J, et al. Mortality variation across Australia: descriptive data for states and territories, and statistical divisions. Aust N Z J Public Health 2000;24:226-33.

17. Burnley $\mathrm{IH}$. Differential and spatial aspects of suicide mortality in New South Wales and Sydney, 1980 to 1991. Aust J Public Health 1994;18:293-304.

18. WHO. International Classification of Diseases, 9th revision (ICD-9). Geneva: World Health Organization, 1975.

19. WHO. The ICD-10 classification of mental and behavioral disorders. Geneva: World Health Organization, 1992.

20. MapInfo Corporation. MapInfo Professional 10.5 User Guide. New York, USA: Maplnfo Corporation, 2010.

21. Arbuckle JL. IBM SPSS Amos 21 User's Guide. NY, USA: IBM Corporation North Castle Drive Armonk, 2012.

22. Loboprabhu S, Molinari V. Severe loneliness in communitydwelling aging adults with mental illness. J Psychiatr Pract 2012;18:20-8.

23. Bekhet AK, Zauszniewski JA. Mental health of elders in retirement communities: is loneliness a key factor? Arch Psychiatr Nurs 2012;26:214-24.

24. Pearson JL, Conwell Y, Lindesay J, et al. Elderly suicide: a multi-national view. Aging Ment Health 1997;1:107-11.

25. Hall WD, Mant A, Mitchell PB, et al. Association between antidepressant prescribing and suicide in Australia, 1991-2000: trend analysis. BMJ 2003;326:1008

26. Hickie IB, Davenport TA, Naismith SL, et al. Treatment of common mental disorders in Australian general practice. Med J Aust 2001;175(Suppl):S25-30.

27. Mackay FR, Dunn NR, Martin RM, et al. Newer antidepressants: a comparison of tolerability in general practice. $\mathrm{Br} J$ Gen Pract 1999;49:892-6.

28. Preskorn SH. Antidepressant drug selection: criteria and options. J Clin Psychiatry 1994;55(Suppl A):6-22.

29. Mojtabai R. The public health impact of antidepressants: an instrumental variable analysis. J Affect Disord 2011;134:188-97.

30. Friedman RA, Leon AC. Expanding the black box-depression, antidepressants, and the risk of suicide. $N$ Engl J Med 2007;356:2343-6.

31. Ozanne-Smith J, Ashby K, Newstead S, et al. Firearm related deaths: the impact of regulatory reform. Inj Prev 2004;10:280-6.

32. Norberry J, Woolner D, Magarey K. After Port Arthur-issues of gun control in Australia. Parliamentary library current issues brief 16, 1995-96. Canberra, Australia: Department of the Parliamentary Library, 1996.
33. AMPC. Australasian Police Ministers' Council (APMC), Special Firearms Meeting, Canberra, 10 May 1996: Resolutions. Canberra Australia, 1996.

34. The Library of Congress. Firearms-Control Legislation and Policy: Australia. http://www.loc.gov/law/help/firearms-control/australia. php\#Firearms (accessed 15 May 2014).

35. Klieve $\mathrm{H}$, Barnes $\mathrm{M}$, De Leo D. Controlling firearms use in Australia: has the 1996 gun law reform produced the decrease in rates of suicide with this method? Soc Psychiatry Psychiatr Epidemiol 2009;44:285-92.

36. McPhedran S, Baker J. Suicide prevention and method restriction: evaluating the impact of limiting access to lethal means among young Australians. Arch Suicide Res 2012;16:135-46.

37. Centers For Disease Control And Prevention. Compressed mortality file (underlying cause-of-death). Wide-Ranging Online Data for Epidemiologic Research (WONDER) database, 2010. http://wonder. cdc.gov/mortSQL.html (assessed 8 Sep 2012).

38. Stark C, Hopkins P, Gibbs D, et al. Trends in suicide in Scotland 1981-1999: age, method and geography. BMC Public Health 2004;4:49

39. Wilkinson D, Gunnell D. Comparison of trends in method-specific suicide rates in Australia and England \& Wales, 1968-97. Aust N Z $J$ Public Health 2000;24:153-7.

40. Williams R, Doessel D, Sveticic J, et al. Accuracy of official suicide mortality data in Queensland. Aust N Z J Psychiatry 2010;44:815-22.

41. ABS. 3303.0. Causes of death, Australia, 2007. Canberra, Australia: Australian Bureau of Statistics, 2009.

42. Rihmer Z, Belso N, Kalmar S. Antidepressants and suicide prevention in Hungary. Acta Psychiatr Scand 2001;103:238-9.

43. Jorm AF, Christensen $\mathrm{H}$, Griffiths KM. The impact of beyond blue: the national depression initiative on the Australian public's recognition of depression and beliefs about treatments. Aust $N Z J$ Psychiatry 2005;39:248-54.

44. Paykel ES, Hart D, Priest RG. Changes in public attitudes to depression during the Defeat Depression Campaign. Br J Psychiatry 1998;173:519-22.

45. Mann JJ, Apter A, Bertolote J, et al. Suicide prevention strategies: a systematic review. JAMA 2005;294:2064-74.

46. Huisman M, Oldehinkel AJ. Income inequality, social capital and self-inflicted injury and violence-related mortality. J Epidemiol Community Health 2009;63:31-7.

47. Chan WS, Yip PS, Wong PW, et al. Suicide and unemployment: what are the missing links? Arch Suicide Res 2007;11:327-35.

48. Lambert $\mathrm{G}$, Reid $\mathrm{C}$, Kaye $\mathrm{D}$, et al. Increased suicide rate in the middle-aged and its association with hours of sunlight. $A m \mathrm{~J}$ Psychiatry 2003;160:793-95.

49. Nicholls N, Butler CD, Hanigan I. Inter-annual rainfall variations and suicide in New South Wales, Australia, 1964-2001. Int J Biometeorol 2006;50:139-43.

50. Fragar LJ, Gray EJ, Franklin RJ, et al. A picture of health: a preliminary report of the health of country Australians. Moree, NSW, Australia: The Australian Agricultural Health Unit, 1997. 